\title{
MECHANISMS IN ENDOCRINOLOGY \\ Medical consequences of doping with anabolic androgenic steroids: effects on reproductive functions
}

\author{
Eberhard Nieschlag ${ }^{1,2}$ and Elena Vorona ${ }^{3}$ \\ ${ }^{1}$ Centre of Reproductive Medicine and Andrology, University of Münster, 48129 Münster, Germany, ${ }^{2}$ Center of \\ Excellence in Genomic Medicine Research, King Abdulaziz University, Jeddah, Saudi Arabia and ${ }^{3}$ Centre of \\ Endocrinology, Diabetology and Rheumatology, Dortmund, Germany
}

Correspondence should be addressed to E Nieschlag Email eberhard.nieschlag@ ukmuenster.de

\begin{abstract}
Anabolic androgenic steroids (AASs) are appearance and performance-enhancing drugs (APEDs) used in competitive athletics, in recreational sports, and by body-builders. The global lifetime prevalence of AASs abuse is $6.4 \%$ for males and $1.6 \%$ for women. Many AASs, often obtained from the internet and dubious sources, have not undergone proper testing and are consumed at extremely high doses and in irrational combinations, also along with other drugs. Controlled clinical trials investigating undesired side effects are lacking because ethical restrictions prevent exposing volunteers to potentially toxic regimens, obscuring a causal relationship between AASs abuse and possible sequelae. Because of the negative feedback in the regulation of the hypothalamic-pituitary-gonadal axis, in men AASs cause reversible suppression of spermatogenesis, testicular atrophy, infertility, and erectile dysfunction (anabolic steroid-induced hypogonadism). Should spermatogenesis not recover after AASs abuse, a pre-existing fertility disorder may have resurfaced. AASs frequently cause gynecomastia and acne. In women, AASs may disrupt ovarian function. Chronic strenuous physical activity leads to menstrual irregularities and, in severe cases, to the female athlete triad (low energy intake, menstrual disorders and low bone mass), making it difficult to disentangle the effects of sports and AASs. Acne, hirsutism and (irreversible) deepening of the voice are further consequences of AASs misuse. There is no evidence that AASs cause breast carcinoma. Detecting AASs misuse through the control network of the World Anti-Doping Agency (WADA) not only aims to guarantee fair conditions for athletes, but also to protect them from medical sequelae of AASs abuse.
\end{abstract}

\section{Introduction}

Medal-winning athletes are the undisputed icons of society. As role models, they are also expected to show impeccable character and behaviour. Society rewards them with admiration and dedication, in no way objecting to exorbitant financial gains by their idols; governments and companies consider athletes' triumphs

\section{Invited Author's profile}

Eberhard Nieschlag is emeritus Professor at the Center of Reproductive Medicine and Andrology, University of Münster, Germany. His clinical and research activities concentrate on reproductive endocrinology and andrology, especially male infertility, testosterone substitution, the aging male, hormonal male contraception and steroid doping.

(C) 2015 European Society of Endocrinology Printed in Great Britain
Published by Bioscientifica Ltd. 
as advertisements for their politics and products respectively. In addition to exhaustive training, this places athletes under tremendous pressure, not only to excel in their discipline, but also to resist the temptation to use any illicit means, e.g. drugs, to enhance performance. 'Play true' is the motto of the World Anti-Doping Agency (WADA), appealing to all athletes to refrain from using illicit drugs, but without the elaborate worldwide network of doping controls and sanctions against doping (www. wada-ama.org, $(1,2))$, WADA's call for fairness would remain without echo. However, doping is not reserved for the small squad of elite athletes, it has spread from the idols at the top to all rank and file participants in sports, from adolescents to seniors. The global lifetime prevalence rate of using anabolic androgenic steroids (AASs) is 6.4\% for males and $1.6 \%$ for females (3). Not only classical sport disciplines are involved; the phenomenon is similarly widespread among bodybuilders, so that the drugs used have been collectively classified as 'appearance and performance-enhancing drugs' (APEDs) and summarised in the WADA Prohibited List 2015 (www.wada-ama.org).

Although doping has been practiced since antiquity, often with placebo or toxic effects, really effective APEDs only became available with the rise of modern pharmacology, and in particular, following the isolation and synthesis of testosterone and AASs. Testosterone came into clinical use shortly after its synthesis in 1935 (4) and its first documented use for doping was by German rowers in 1952 (to maintain their marital duties during exhausting training) and by Russian weight lifters in 1954 to enhance their power. Since then AASs lead the lists of APEDs worldwide and among these testosterone is used in almost $50 \%$, be it in the 4500 doping-positive samples collected by WADA worldwide in 2012 (5) or be it among black market substances confiscated by customs and police (6) (Table 1).

As all licensed testosterone and AAS preparations are available only by prescription, the drug sources remain obscure. In part, these substances are no longer or have never been on the open market. There have been instances og doctors prescribing AASs especially under pressure from bodybuilders, who undertake any risk to become champions. Surveys among fitness centre clientele revealed that up to half of APED users obtained the drugs with or without prescription from physicians or pharmacies $(7,8)$. Labs in Eastern Europe, Asia and South America producing multitudes of AASs offer them for sale on the internet which, next to gyms and fitness studios, has become the major source of AASs. When counted in November 2011, there were 328000 internet pages accessible under the
Table 1 Anabolic androgenic steroids (AASs) constitute $87 \%$ of illegal appearance and performing-enhancing drugs (APEDs) confiscated by customs or on the black market in Germany 2010-2013; more than half are testosterone preparations (data from (6)).

\begin{tabular}{l}
\hline AAS \\
\hline Testosterone preparations \\
Testosterone enanthate \\
Testosterone propionate \\
Testosterone isocaproate \\
Testosterone decanoate \\
Testosterone cypionate \\
Testosterone phenylpropionate \\
Testosterone (unesterified) \\
Total \\
Metandienone \\
Nandrolone \\
Trenbolone \\
Stanozolol \\
Oralturinabol \\
Boldenone \\
Drostanolone \\
Oxandrolone \\
Oxymetholone \\
Methenolone \\
Methyldrostanolone \\
Total
\end{tabular}

\begin{tabular}{r}
$\mathbf{K g}$ \\
\hline 81.9 \\
32.1 \\
18.0 \\
5.5 \\
5.2 \\
1.5 \\
1.3 \\
145.5 \\
34.3 \\
26.6 \\
15.9 \\
10.3 \\
10.0 \\
8.9 \\
4.7 \\
1.2 \\
1.2 \\
0.3 \\
0.3 \\
259.3
\end{tabular}

search term 'steroids for sale' (9)! Furthermore, AASs may be added to food supplements - often undeclared on the label $(10,11,12)$ or found in phytopharmaka and animal organ extracts. For example, musk pods used in Chinese traditional medicine contain 16 different, undeclared AASs, as discovered in doping controls (13). Finally, secret but official programmes of sport organisations or states may provide AASs and other APEDs to their athletes, as demonstrated by the systematic doping programme of the former German Democratic Republic (GDR) in the 1970s and 1980s, which became evident after the collapse of that règime in 1989 (14).

AASs - as all other APEDs - may have not only the desired effect, but also adverse side effects, resulting from the combination of different AASs in extremely high doses with other drugs and from duration of administration over periods ranging from months to many years. Due to the secret nature of this drug abuse type, doses and duration are mostly unknown and properly controlled clinical trials do not exist. Hence the scientific assessment of the sequelae of AASs abuse relies on case reports and on a few retrospective investigations, making a review of the field in the age of evidence-based medicine extremely difficult and frustrating. Nevertheless, this review is intended to inform the endocrinologist about symptoms and diseases caused 
Table 2 Side effects of high-dose steroids on reproductive and sexual functions/organs.

\begin{tabular}{l} 
In men \\
\hline Suppression of gonadotropins \\
Suppressions of spermatogenesis \\
Decrease in testis volume \\
Infertility \\
Baldness \\
Gynaecomastia \\
Loss of libido \\
Erectile dysfunction \\
Profuse sweating \\
Striae distensae \\
Acne \\
Global effect: anabolic \\
$\quad$ steroid-induced \\
$\quad$ hypogonadism (ASIH)
\end{tabular}

by AASs which, without specific knowledge, may be misinterpreted while searching for their origin. Proper diagnosis is further hindered by the reluctance of the doped patient to admit the consumption of AASs and being ignorant about their possible serious side effects.

This review highlights the effects of testosterone and AASs on male and female reproductive functions and includes effects on the skin and its appendices as secondary sexual characteristics (overview in Table 2). For adverse effects on other organ systems, the reader is referred to previous reviews (e.g. $(15,16,17,18,19)$ ). For the sake of manageability, testosterone and AASs (including designer steroids) are collectively referred to as AASs, although both chemical structure and biological profiles of individual AASs differ. In general, the effects and side effects of specific AASs depend on their chemical structure. The full spectrum of biological action requires that the androgen can be aromatised to oestradiol as well as reduced to $5 \alpha$-dihydrotestosterone. As indicated in Fig. 1, the most frequently used AASs, such as, testosterone, boldenone, metandione and nortestosterone, can be aromatised as well as $5 \alpha$-reduced, while fluoxymesterone and formebolone can be $5 \alpha$-reduced but not aromatised, and some AASs can be neither aromatised nor $5 \alpha$-reduced, especially those that are dihydrotestosterone derivatives (Fig. 1). In addition, the genetic disposition of the individual athlete may modify the reaction of androgenic substances, as exemplified by the androgen receptor polymorphism modulating testosterone activity (20). However, keeping these apart is difficult due to the varying combinations and doses in addition to the often practiced doping polypharmacy $(21,22)$, including erythropoietin, insulin, IGF1, thyroxine, clenbuterol, amphetamines, diuretics, etc. However, the unique common feature of alkylation in the $17 \alpha$-position of the androgen molecule should be pointed out because these AASs are potentially severely liver toxic (Fig. 1). AASs abuse is also characterised by 'stacking and cycles', i.e. increasing doses over time and changing preparations and their combinations alternating with AASs-free periods in order to maximise desired effects

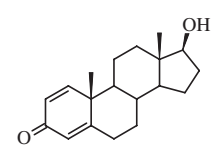

Boldenone 1,2

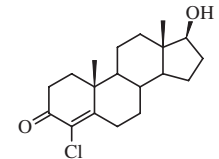

Clostebol

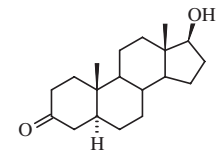

Dihydrotestosterone 2

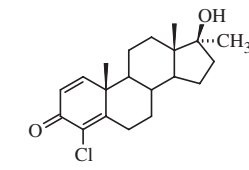

Dehydrochloromethyltestosterone 2,3

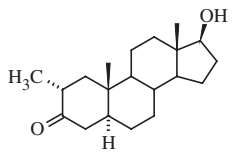

Drostanolone

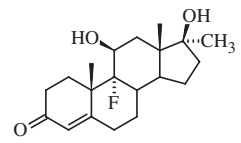

Fluoxymesterone 2,3

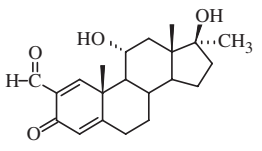

Formebolone 2,3

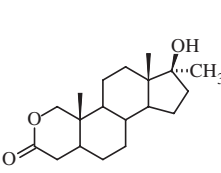

Oxandrolone 2,3
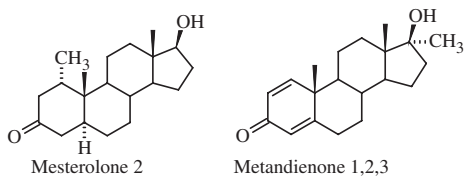

Metandienone 1,2,3

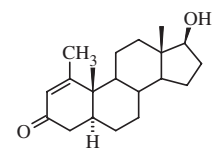

Methenolone 2
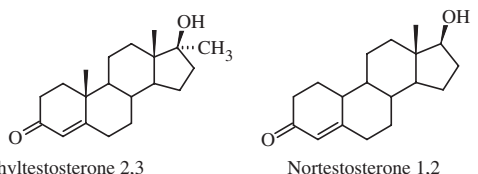

Nortestosterone 1,2
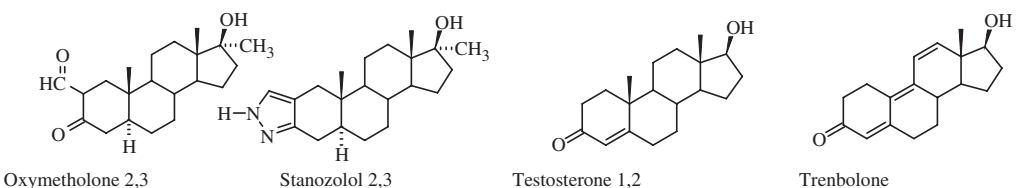

Trenbolone

\section{Figure 1}

Anabolic androgenic steroids (AASs) detected most often in international doping control tests. 1: AASs that can be aromatised, 2: AAS that are or can be $5 \alpha$-reduced, 3: AASs with the liver-toxic $17 \alpha$-alkylation (adapted from (1)). 
and minimise side effects. Whether these regimens indeed fulfill their purpose cannot be assessed as they are based on trial and error and appropriate studies do not exist.

\section{Effects of AASs on male reproductive functions}

\section{Suppression of spermatogenesis}

As endogenous testosterone is the major regulator of the hypothalamo-pituitary-testicular axis, it is not surprising that exogenous testosterone and AASs exert a suppressive effect on the hypothalamo-pituitary system. The resulting suppression of luteinizing hormone (LH) and folliclestimulating hormone (FSH) leads to a decrease in intratesticular testosterone and secreted testosterone, as well as to a decrease in spermatogenesis and sperm production. This effect forms the basis for clinical trials in hormonal male contraception. As there are no systematic investigations of the effects of doping with high-dose AASs on testicular function, contraceptive trials may serve as a model for what happens under AASs suppression.

Male hormonal contraceptive trials use testosterone alone in therapeutic doses or in combination with gestagens to induce azoospermia or severe oligozoospermia compatible with contraceptive protection (for review (23)). Testosterone derivatives used for doping, such as 19-nortestosterone and MENT, have also been applied in contraceptive trials $(24,25)$. The kinetics of sperm suppression and recovery are quite well known from these carefully conducted trials using therapeutic doses $(26,27)$. Of 1549 healthy eugonadal men participating in 30 different clinical trials, after cessation of medication, $67 \%$ showed a return to sperm concentrations above 20 million/ml within 6 months, 90\% within 12 months, 96\% within 16 months and $100 \%$ within 24 months (26). While the different regimens used in the 30 trials were not identical, they used similar steroid doses; the differences in recovery time appear to be determined more by the characteristics of the individual than by the therapeutic regimen. Nevertheless, all men returned to fertile levels of sperm counts. Thus a 6 to 24-month span provides a time frame for recovery in AASs abusers, although it has to be kept in mind that doses used for doping far exceed those used for male contraception, and therefore even longer periods may be anticipated.

These results may help to interpret case reports and small retrospective studies in AASs abusers. These show a wide spectrum of sperm counts in AASs users under treatment, as well as after cessation of abuse, ranging from normal levels to azoospermia (Fig. 2) $(28,29)$. LH and

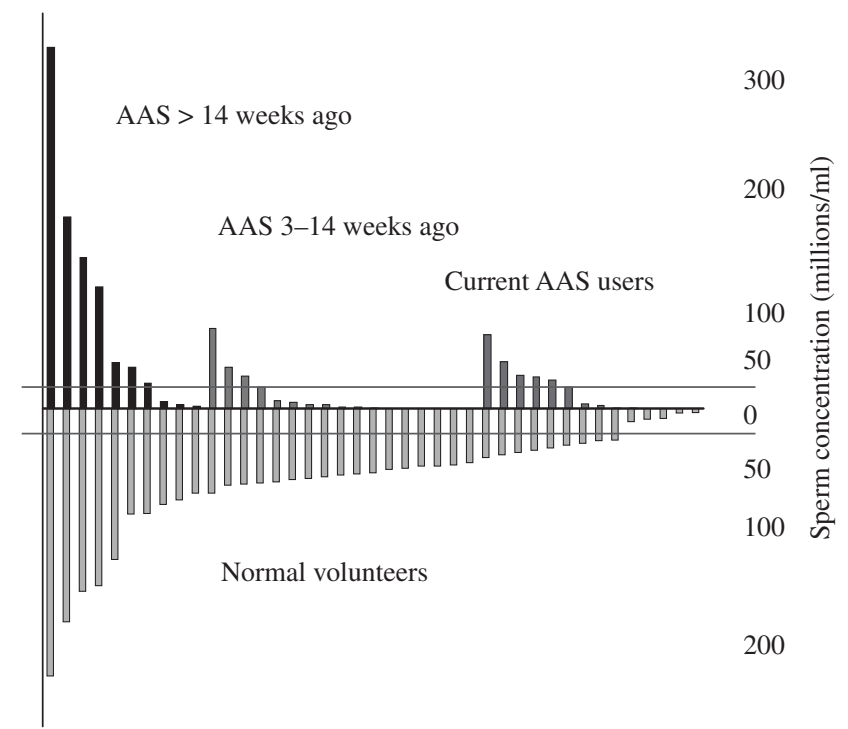

\section{Figure 2}

Sperm concentrations in 41 bodybuilders currently using anabolic steroids, 3-14 weeks ago or $>14$ weeks ago (upper part) and in 41 drug-free volunteers (lower part). The bars represent sperm concentrations from individual body-builders (upper panel) and from normal volunteers (lower panel).

The horizontal lines indicate a concentration of $20 \mathrm{million} / \mathrm{ml}$ as lower limit of normal (modified from (28)).

FSH correlate grossly with sperm counts, i.e. the lower the gonadotropins, the lower the sperm counts tend to be. Parallel to the decline in spermatogenesis, testicular volumes decrease significantly because the tubules occupy about $95 \%$ of the testes volume and their atrophy causes shrinkage of the testis. Varying doses, preparations, and combinations of AASs and other APED make it difficult to draw general conclusions from individual observations, but it is clear that the recovery of sperm counts correlates positively with duration of time since last intake of AASs, as do sperm morphology and motility (Fig. 2). As AASs may be abused for many years at high doses and in varying combinations, it is impossible to predict accurately their impact on spermatogenesis without proper investigations.

In some AASs abusers, recovery may take irritatingly long. This, in addition to individual predisposition, is most likely due to the depot effects of the huge steroid concentrations consumed $(30,31)$. For example, after termination of nandrolone abuse metabolites could still be detected in urine after more than a year in some men (32). In other candidates, sperm counts may not reach the normal range after cessation of doping, possibly due to preexisting fertility problems. When infertile men with 
subnormal sperm counts were included in a contraceptive trial using testosterone undecanoate alone, all returned to their (subnormal) baseline levels after cessation of testosterone undecanoate administration, but did not become better or worse than before the trial (33). In analogy, those AASs users who apparently do not return to normal sperm counts may never have had normal values before initiation of AASs abuse.

In conclusion, to date there is no indication that AASs abuse causes permanent damage to spermatogenesis, although suppression may cause transient azoospermia and recovery may take up to 2 years. However, no systematic investigations exist to provide a definitive answer.

Considering the great number of teenage boys using AASs, the question arises whether their use by boys around puberty may be harmful to spermatogenesis. Although systematic investigations in pubertal AASs users are lacking, treatment of over-tall boys with high doses of testosterone - close to doping doses - for reduction of final height provides an analogy. Initially it was suspected that this treatment would be harmful to the testes and leave permanent damage. However, when the proper control groups were co-investigated, the incidence of subnormal semen parameters was the same in both groups $(34,35)$, indicating that at this age the testes do not differ from adult men in their capacity to recover from suppression.

\section{Testicular tumours}

In connection with AASs abuse, testicular germ cell tumours have not been reported in the literature. A single case of a leiomyosarcoma in a former GDR weightlifter has been reported. He used oral turinabol at high doses (up to 20 tablets/day) from 18 to 23 years of age. He developed gynaecomastia under the treatment and was, at the age of 32 , operated for a unilateral intratesticular leiomyosarcoma (36). As these tumours are extremely rare and have been described in hamsters after treatment with testosterone propionate and diethylstilbestrol (37), the authors suspected a causal relationship between AASs abuse and the sarcoma. As this remains the only reported case, possible involvement of AASs in the pathogenesis of the tumour remains unclear.

\section{Hypogonadism induced by anabolic steroids}

In addition to decreased sperm counts and testes volumes, some AASs abusers experience lack of libido and erectile function as well as other signs of hypogonadism. This occurs especially in those men abusing aromatisable AASs, resulting in high oestrogen levels. Although physiological levels of oestrogens are necessary for normal sexual function (38), the extremely high doses and the imbalance between testosterone and estradiol appear to be the cause of sexual dysfunction in these cases. This may also occur during the recovery phase after termination of exogenous AASs supply, when endogenous production has not yet resumed full activity. This type of hypogonadism (31) has been referred to as 'anabolic steroid-induced hypogonadotrophic hypogonadism' (39) and more recently, simply as 'anabolic steroid-induced hypogonadism' (ASIH) (40, 41). In a large US urology department, 96 of 6033 (=1.6\%) patients consulting for hypogonadism suffered from ASIH. One-quarter of these patients presented with infertility and three quarters with sequelae of hypogonadism (41). Many of these AASs abusers were first overlooked and only diagnosed after renewed interviewing following inconclusive investigations. This reflects the fact that patients seeking medical care only reluctantly admit to AASs abuse, and targeting AASs abuse directly should be part of the routine work-up of hypogonadal men (17).

Cessation of AASs abuse is the prime measure to treat ASIH. In addition, various therapeutic attempts have been undertaken to overcome ASIH and to hasten recovery. Human chorionic gonadotropin (hCG) has been given in individual cases (42), and has also been combined with tamoxifen or clomiphene to counteract the increased oestrogen levels under hCG, inducing or worsening gynecomastia $(43,44)$. However, hCG administration simultaneously with AASs in order to maintain fertility in power athletes showed an increase in morphologically abnormal sperm in comparison with a control group receiving only AASs. This may be due to the lack of FSH under stimulation by hCG alone (45). Therefore, although sperm counts were maintained under this treatment, fertility may still be compromised due to deteriorated sperm morphology. In cases with erectile dysfunction, PDE5 inhibitors have been prescribed, but again no systematic studies exist.

The continuing lack of conclusive studies prevents clear recommendations on how to treat ASIH except to stop AASs and other drug intake immediately and to await recovery in patience. It also remains ethically questionable whether the consequences of hormone abuse should be counteracted by additional hormone treatment, when normal conditions can be reconstituted by strict termination of abuse and waiting for spontaneous recovery. Gonadotropin treatment may be justified only if no improvement has been observed within 24 months $(30,46)$. 


\section{Prostate}

Prostate development and growth are dependent on androgens (47). The prostate grows during puberty and the small prostates of hypogonadal patients attain normal adult dimensions under testosterone treatment. Furthermore, androgens are often considered promoters or even initiators of prostate carcinoma so that one would expect a high rate of benign prostatic hypertrophy (BPH) and prostate carcinoma in AASs abusers, often exposed to high doses of various AASs. Despite these considerations, only one case has been reported of a bodybuilder who used combinations of different oral and injectable AASs at high doses over a time span of 18 years, occasionally augmented by growth hormone injections, who developed an adenocarcinoma of the prostate at age 40 (48). Considering this drug anamnesis, it is tempting to suspect a causal relationship, but the lack of further case reports or systematic investigations do not support this suspicion (49). The observation that the type and duration of sport activities may influence the occurrence of prostate carcinoma (as well as erectile dysfunction and infertility) makes interpretation of AASs abuse even more difficult. In cyclists over 50 years of age, a clear positive correlation between the incidence of prostate cancer and hours of weekly cycling time ( $<3.75$ vs $>8.5 \mathrm{~h} /$ week) was found (50). Furthermore, the observation that hypogonadal men treated with therapeutic doses of testosterone do not suffer from a higher incidence of prostate carcinoma than patients not treated with testosterone (51) supports the hypothesis that prostate carcinoma develops independently of possible androgen treatment.

Similarly, there are no clear indications, case reports or systematic investigations demonstrating that AASs abuse causes BPH. As shown in the preclinical model of the cynomolgus monkey, co-administration of testosterone and norethisterone prevents the testosterone-induced prostate growth and hypertrophy (52). As several AASs also have gestagenic activity in addition to androgenic effects, some AASs may prevent testosterone-dependent prostate growth when given in combination, and this may explain the low incidence of BPH in AASs abusers.

\section{Effects of AASs in women}

\section{Reproductive functions}

In females, delayed menarche, dysmenorrhoea, oligomenorrhoea, secondary amenorrhoea, anovulation and, as their consequence, infertility are the changes most often attributed to AASs abuse. However, physical and athletic activity often result in reproductive disregularities due to disruption of the GNRH pulse generator at the hypothalamic level. This leads to a decrease in LH and FSH and thus to decreased oestrogen production $(53,54)$. A populationbased survey among 3887 Norwegian women revealed that those who were physically active on most days were 3.2 times more likely to have fertility problems than inactive women. Exercising to exhaustion caused a further increase in fertility problems. However, after terminating the active sport, the number of nulliparous women was the same in the inactive and formerly active women (55). When the influence of physical activity in 2232 women undergoing IVF treatment was investigated, those women who exercised 4 or more hours per week for 1-9 years were $40 \%$ less likely to experience a live birth in the first IVF cycle than those who did not exercise at all (56). Among 717 of 849 elite female athletes participating in the 2011 IAAF Championship using neither hormonal contraceptives nor AASs, 168 were oligo- or amenorrhoic. Only five of the 849 women were identified as AASs abusers (57). This indicates that ovulation and menstrual disorders leading to infertility are common among physically active women and especially among competitive athletes, even without AASs abuse.

Furthermore, the type of sport and the body composition required influence reproductive functions. Ballet dancers and competitive gymnasts start strenuous training at an early age and retain a lean physique with extremely low fat mass. Consequently, their menarche occurs 2 years later than in less active girls. In runners, menstrual disorders occur in $25 \%$ on average, with frequency correlating positively with distances covered per week. Swimmers have fewer irregularities than other athletes, probably due to their higher oestrogen-generating fat mass than other sportswomen (for review $(53,58)$ ). The lack of oestrogens may become so severe that the syndrome of the 'female athlete triad' (disturbed energy balance due to disturbed eating behaviour, menstrual irregularities and low bone mineral density) has been identified as a severe consequence of intensive sport activity $(59,60)$. The high frequency of reproductive anomalies among female athletes highlights the difficulty in disentangling the effects of exhausting sport activities and of AASs abuse in the absence of controlled studies and based on only few case reports. In cases of the female athlete triad, it has been speculated that (moderate) AASs intake could prevent some of the symptoms.

To approach the possible influence of androgens on the female organism, investigations on the therapeutic use 
of testosterone in women may be consulted. A large investigation with the aim of evaluating the side effects of testosterone administration in therapeutic doses in women showed no significant differences concerning the frequency of cerebrovascular diseases, coronary heart disease, breast carcinoma, deep venous thrombosis/lung embolism, diabetes mellitus, or acute hepatitis between women receiving testosterone therapy and the control group $(61,62)$.

If changes in the reproductive system due to suppression of the hypothalamic-pituitary-gonadal axis, such as dysmenorrhoea, secondary amenorrhoea with anovulation or reduction of breast size, are attributed to AASs abuse, they should also be reversible if caused by AASs. It can take weeks or months up to complete recovery of the axis. In some cases, it has been reported that after cessation of AASs administration in women it took up to 20 months until testosterone concentrations in serum dropped to normal levels (62), correlating with observations on spermatogenesis in male AASs abusers (see above). Concerning possibly irreversible side effects of AASs use in women, such as clitoris hypertrophy, no well-documented case reports or studies are available.

\section{Hirsutism and alopecia}

Hirsutism and alopecia are frequent, but in most instances reversible side effects of androgen and AASs use in women $(63,64,65)$. Assessment of body hair and hirsutism has to take ethnic dispositions into account. The degree of increased facial or body hair growth depends on dose and duration of AASs abuse and can be described according to the hirsutism score by Ferriman-Gallwey, established in 1961. Based on the intensity of hair growth in nine face/body areas, hirsutism can be diagnosed as mild, moderate, or severe (66). However, proper analysis of the grade of hirsutism and alopecia in AASs abusers has not been undertaken.

\section{Deepening of the voice}

Lowering of the voice is caused by growth of the larynx in girls and by thickening of the vocal chords in women after puberty and can be monitored objectively. As laryngeal tissue has androgen receptors, the voice is part of the virilisation that androgenic substances and AASs can cause in women. The voice is an important phenotypic characteristic of a person's identity and changes are easily recognised during social contacts. The voice change can be so pronounced that on the telephone women may be mistaken for men. It is accompanied by hoarseness which may intensify upon longer use of the voice. This dysphonia may become a problem for teachers, actors, and singers who are professionally dependent on their voices.

Such voice alterations are observed with endogenous elevation of testosterone levels e.g. congenital adrenal hyperplasia (67) or in women sensitive to the androgenic action of some oral contraceptives. Effects of androgens prescribed for other than doping purposes in women (endometriosis, climacteric complaints, low libido, cellulitis etc.) have been described in some detail $(68,69,70)$. In low-dose transdermal testosterone trials, $12 / 545$ postmenopausal women receiving placebo and 15/549 on testosterone reported voice changes (64), emphasising the importance of controlled studies when evaluating subjective parameters.

In contrast to acne, hirsutism, alopecia and mammary atrophy, deepening of the voice due to AASs tends to be irreversible. However, although deepening of the female voice is mentioned in all pertinent reviews dealing with AASs abuse, it is surprising that no systematic investigations exist, and even case reports are very rare. Most information is anecdotal and some comes from telephone interviews or hotlines. For example, 11\% of 217 women consulting the anti-doping hotline of a Swedish university hospital complained of hoarseness or lowering of the voice (71); however, as only those with complaints use such hotlines, the figures are not representative. As changes in the voice are mostly irreversible, androgen application must be suspended at the earliest sign of symptoms, if they are to be avoided.

\section{The risk of breast cancer}

Breast cancer is the most frequent carcinoma in women with 96 new cases per 100000 women and year in Western Europe (72). This high prevalence has to be kept in mind when considering any additional changes in AASs abusers. The effect of exogenous androgens on the development of breast cancer has been discussed controversially in the scientific literature. The lack of controlled studies and epidemiologic investigations contributes to the uncertainties so that indirect evidence from other clinical situations has to be referred to.

In premenopausal women - the group to which most AASs abusers belong - most studies do not demonstrate an association between serum testosterone levels and breast cancer risk (62). In postmenopausal women, however, a small increase in the risk for breast cancer in correlation 
with testosterone and androstenedione serum levels was found, but only in $\mathrm{E}+/ \mathrm{P}+$ cancers (73).

In recent years, low-dose testosterone - mainly transdermal - has been used for the treatment of female sexual dysfunction, in particular of hypoactive sexual desire syndrome (HSDD). In this context, the risk of breast cancer has become a concern. Recent reviews $(62,74)$ and practice guidelines (75) find no evidence for an increased risk, but also conclude that no randomised controlled trials (RCTs) have been of sufficient size or duration to provide a definitive answer concerning the impact of testosterone on breast cancer risk.

Experience with long-term hormonal therapy in transsexuals (female-to-male) aiming at virilisation (standard therapy: testosterone enanthate $250 \mathrm{mg}$ i.m. every second week or testosteone undecanoate $1000 \mathrm{mg}$ every 10-12 weeks for 2-3 years before surgical therapy, e.g. mastectomy, ovarectomy and hysterectomy, and for years after that) shows no increased risk for breast cancer $(76,77)$. Since the 1970s, when hormonal therapy of transsexuals was first documented, only one clinical case has been reported; in this case a mamma carcinoma of the residual breast tissue developed 10 years after bilateral mastectomy and continuous testosterone therapy (78).

The polycystic ovary syndrome (PCOS) is characterised by a significant increase in the testosterone concentration in blood and often serves as a model for long-term testosterone exposure in women. Studies showed that the risk for breast cancer in these women does not increase (79).

Exogenous androgens are partially metabolised to oestrogens in breast tissue (see Table 1). However, not all synthetic androgens are subject to aromatisation, e.g. tibolone and its metabolites cannot be aromatised (80). This also applies to the metabolism of oralturinabol (chlordehydromethyltestosterone) predominantly used in the former GDR. Unless taken at extremely high doses, the molecule is not aromatised, so that oestrogenic side effects become clinically irrelevant (81).

A large randomised study showed that postmenopausal women receiving oestrogens exclusively did not have an increased risk of mammary carcinoma, in contrast to women who received an oestrogen/gestagen combination (82). The age of the patient and the duration of oestrogen therapy are considered as risk factors for the development of breast cancer in women. Comparable results have also been shown in other studies $(83,84)$. However, women who received hormone replacement therapy (oestrogen or oestrogen/gestagen preparations) at the time point of the evaluation, in comparison with those who had never taken hormonal drugs, had a higher risk for development of breast cancer. Women who in the past had received hormonal therapy did not have a higher risk for mamma carcinoma.

It has also been shown that additional administration of testosterone during hormonal replacement therapy in postmenopausal women (oestrogen-gestagen preparations) inhibited the proliferation of breast cells and thereby decreased the risk of mammary carcinoma (85). A recent 5 -year interim analysis of a 10 -year prospective study has demonstrated that in women treated with testosterone implants the incidence of breast cancer was significantly reduced compared with untreated women (86).

In animals and also in postmenopausal patients androgens (e.g. testosterone, dihydrotestosterone (DHT)) blocked proliferation of breast cells in vitro, caused by oestrogens as well as expression of oestrogen receptor genes $(87,88,89,90,91)$. The antiproliferative and proapoptotic actions of androgens are probably mediated through the androgen receptor, despite the potential of testosterone to metabolise to oestrogens (79). Before these interrelations were known, advanced stages of mammary gland carcinoma had even been treated with testosterone from the 1940s until the 1970s (92). The underlying clinical experience was that testosterone inhibits rather than proliferates a breast carcinoma. A genetic disposition concerning mutations in BRCA1 and BRCA2 genes (breast cancer gene) can exhibit a higher risk for the development of a breast carcinoma.

In conclusion, there are no appropriate epidemiologic studies which clearly document or negate a causal connection between the administration of AASs in young female athletes and the development of breast carcinoma later in life. Nor is there an accumulation of case reports which would argue for such a connection. Indirectly, it can be assumed that the use of AASs at young ages cannot be causal for breast cancer. However, as in the case of clinical low-dose testosterone treatment, sufficiently powered epidemiologic studies are required to provide a definitive answer concerning the breast cancer risk in AASs abusers.

\section{Side effects of AASs on the skin in both sexes}

The use of AASs can very rapidly lead to cutaneous changes in previously unaffected athletes so that the dermatologist may be among the first physicians to be confronted with AASs abuse. AASs act through the androgen receptor, presenting in epidermal and follicular keratinocytes, 
sebocytes, sweat gland cells, dermal papilla cells, dermal fibroblasts, endothelial cells, and genital melanocytes. The effects are mediated through affecting the sebaceous gland growth and differentiation, hair growth, epidermal barrier homeostasis and wound healing (93). The AR polymorphism appears to play a role in the severity of symptoms (93).

The most frequent skin manifestations are acne vulgaris, oily skin, seborrhoea, striae, hirsutism and male pattern alopecia (64). The incidence of acne in AASs abusers ranges from $17 \%$ in persons consulting a Swedish anti-doping hotline (71) to over $50 \%$ of athletes taking part in a questionnaire aiming to identify unsupervised AASs regimens and side effects of AASs (94). After elimination of the causal agent, these changes are mostly reversible. To speed up recovery, anti-androgen therapy with cyproterone acetate or spironolactone may be tried (93). However, severe forms of AASs-induced acne conglobata will leave extensive scarring on the affected skin areas (95).

After acne, striae distensae as a result of rapid muscular hypertrophy, supported by AASs intake, is the most prevalent skin side effect in athletes, especially in bodybuilders. Over $40 \%$ of athletes complained about stretch marks of the skin (96) with typical localisation in the musculus pectoralis or upper arm region. After discontinuation of drug misuse, striae can persist as white streaks (70).

\section{Conclusion}

There is a dearth of controlled clinical trials and long-term observations on the side effects of AASs (and other APEDs), and our knowledge on adverse effects is based only on case reports and a few retrospective investigations. Strangely enough, medicine had turned a blind eye on APEDs. For a long time, scientific medicine even negated positive effects by AASs on muscle mass and strength, as documented in a 1991 meta-analysis concluding from a Medline search for publications (1966-1990) that there was no convincing evidence that AASs were increasing muscle power (97). This conclusion was partly based on the fact that AASs doses used in academic studies were in the range of therapeutic replacement doses, far below the doses and combinations used in the real doping world. Bhasin et al. (98) were among the first to apply testosterone doses exceeding clinical replacement levels in their controlled studies and demonstrated a clear positive effect on muscle strength. However, carrying out prospective RCTs on short- and long-term adverse effects of AASs and other APEDs are impossible because; i) supraphysiological doses, long-term duration and the combination of AASs with other drugs would be unethical; ii) some AASs are not licenced drugs with no or only limited toxicology available; iii) high-risk behaviour and lifestyle factors of the doping individuals cannot be re-created in the setting of a RCT; iv) AASs may be hidden in food supplements and are not easily accessible; and v) studies extending over years and decades are unattractive to researchers (19). Under current circumstances, the recent US Endocrine Society's Scientific Statement Task Force (SSTF) has recommended the following: i) establishing prospective observational cohort studies (registries) to determine longterm health effects of AASs and APED use; ii) establishing epidemiologic surveys to determine the prevalence of AASs and APED use in the general population; iii) carrying out human and animal studies to determine the mechanisms by which APEDs exert their adverse effects; and iv) conducting randomised trials of various therapeutic strategies to treat adverse effects of AASs and APED use (19). In addition, as athletes, bodybuilders and fitness studio customers appear to have only vague knowledge of the side effects of AASs, which they often belittle in the light of the relatively few severe long-term problems in relationship with the vast number of AASs abusers (99), more education of consumers, as well as athletic educators and health care providers, about the possible sequelae of AASs and APED abuse is mandatory to prevent negative long-term effects (100).

\section{Declaration of interest}

The authors declare that there is no conflict of interest that could be perceived as prejudicing the impartiality of the review.

\section{Funding}

This review did not receive any specific grant from any funding agency in the public, commercial or not-for-profit sector.

\section{Acknowledgements}

Language editing of the manuscript by Susan Nieschlag MA is gratefully acknowledged

\section{References}

1 Schänzer W \& Thevis M. Detection of illegal use of androgens and selective androgen receptor modulators. In Testosterone: Action, Deficiency, Substitution, 4th edn, ch 24, pp 517-534. Eds E Nieschlag, HM Behre \& S Nieschlag. Cambridge: Cambridge University Press, 2012. 
2 Sottas PE \& Vernec A. Current implementation and future of the Athlete Biological Passport. Bioanalysis 20124 1645-1652. (doi:10.4155/bio.12.130)

3 Sagoe D, Molde H, Andreassen CS, Torsheim T \& Pallesen S. The global epidemiology of anabolic-androgenic steroid use: a meta-analysis and meta-regression analysis. Annals of Epidemiology 201424 383-398. (doi:10.1016/j.annepidem.2014.01.009)

4 Nieschlag E \& Nieschlag S. Testosterone deficiency: a historical perspective. Asian Journal of Andrology 201416 161-168. (doi:10.4103/ 1008-682X.122358)

5 Geyer H, Schänzer W \& Thevis M. Anabolic agents: recent strategies for their detection and protection from inadvertent doping. British Journal of Sports Medicine 201448 820-826. (doi:10.1136/bjsports2014-093526)

6 Krug O, Thomas A, Walpurgis K, Piper T, Sigmund G, Schänzer W, Laussmann $\mathrm{T} \&$ Thevis M. Identification of black market products and potential doping agents in Germany 2010-2013. European Journal of Clinical Pharmacology 201470 1303-1311. (doi:10.1007/s00228014-1743-5)

7 Striegel H, Simon P, Frisch S, Roecker K, Dietz K, Dickhuth HH \& Ulrich R. Anabolic ergogenic substance users in fitness-sports: a distinct group supported by the health care system. Drug and Alcohol Dependence 200681 11-19. (doi:10.1016/j.drugalcdep.2005.05.013)

8 Raschka C, Chmiel C, Preiss R \& Boos C. Recreational athletes and doping - a survey in 11 gyms in the area of Frankfurt/Main. Münchener Medizinische Wochenschrift 2013155 (Suppl 2) 41-43.

9 Brennan BP, Kanayama G \& Pope HG Jr. Performance-enhancing drugs on the web: a growing public-health issue. American Journal on Addictions/American Academy of Psychiatrists in Alcoholism and Addictions 201322 158-161. (doi:10.1111/j.1521-0391.2013.00311.x)

10 Van Thuyne W, Van Eenoo P \& Delbeke FT. Nutritional supplements: prevalence of use and contamination with doping agents. Nutrition Research Reviews 200619 147-158. (doi:10.1079/NRR2006122)

11 Geyer H, Parr MK, Koehler K, Mareck U, Schänzer W \& Thevis M. Nutritional supplements cross-contaminated and faked with doping substances. Journal of Mass Spectrometry 200843 892-902. (doi:10.1002/jms.1452)

12 Rahnema CD, Crosnoe LE \& Kim ED. Designer steroids over-the-counter supplements and their androgenic component: a systematic review on an increasing problem. Andrology 20153 150-155. (doi:10.1111/andr.307)

13 Thevis M, Schänzer W, Geyer H, Thieme D, Grosse J, Rautenberg C, Flenker U, Beuck S, Thomas A, Holland R et al. Traditional Chinese medicine and sports drug testing: identification of natural steroid administration in doping control urine samples resulting from musk (pod) extracts. British Journal of Sports Medicine 201347 109-114. (doi:10.1136/bjsports-2012-090988)

14 Franke WW \& Berendonk B. Hormonal doping and androgenization of athletes: a secret program of the German Democratic Republic government. Clinical Chemistry 199743 1262-1279.

15 Hartgens F \& Kuipers H. Effects of androgenic-anabolic steroids in athletes. Sports Medicine 200434 513-554. (doi:10.2165/00007256200434080-00003)

16 Sjöqvist F, Garle M \& Rane A. Use of doping agents, particularly anabolic steroids, in sports and society. Lancet 2008371 1872-1882. (doi:10.1016/S0140-6736(08)60801-6)

17 Basaria S. Androgen abuse in athletes: detection and consequences. Journal of Clinical Endocrinology and Metabolism 201095 1533-1543. (doi:10.1210/jc.2009-1579)

18 Vorona E \& Nieschlag E. Sequelae of doping with anabolic steroids. In Testosterone: Action, Deficiency, Substitution, 4th edn, ch 25, pp 535-546. Eds E Nieschlag, HM Behre \& S Nieschlag. Cambridge: Cambridge University Press, 2012.

19 Pope HG Jr, Wood RI, Rogol A, Nyberg F, Bowers L \& Bhasin S. Adverse health consequences of performance-enhancing drugs: an Endocrine
Society scientific statement. Endocrine Reviews 201435 341-375. (doi:10.1210/er.2013-1058)

20 Zitzmann M \& Nieschlag E. Androgen receptor gene CAG repeat length and body mass index modulate the safety of long-term intramuscular testosterone undecanoate therapy in hypogonadal men. Journal of Clinical Endocrinology and Metabolism 200792 3844-3853. (doi:10.1210/jc.2007-0620)

21 Skarberg K, Nyberg F \& Engstrom I. Multisubstance use as a feature of addiction to anabolic-androgenic steroids. European Addiction Research 200915 99-106. (doi:10.1159/000199045)

22 Dodge T \& Hoagland MF. The use of anabolic androgenic steroids and polypharmacy: a review of the literature. Drug and Alcohol Dependence 2010114 100-109. (doi:10.1016/j.drupalcdep2010.11.011)

23 Nieschlag E. Clinical trials in male hormonal contraception. Contraception 201082 457-470. (doi:10.1016/j.contraception.2010.03.020)

24 Schürmeyer T, Knuth UA, Belkien L \& Nieschlag E. Reversible azoospermia induced by the anabolic steroid 19-nortestosterone. Lancet 19841 417-420.

25 Nieschlag E, Kumar N \& Sitruk-Ware R. 7 $\alpha$-methyl-19-nortestosterone (MENTR): the Population Council's contribution to research on male contraception and treatment of hypogonadism. Contraception $2013 \mathbf{8 7}$ 288-295. (doi:10.1016/j.contraception.2012.08.036)

26 Liu PY, Swerdloff RS, Christenson PD, Handelsman DJ, Wang C \& Hormonal Male Contraception Summit Group. Rate, extent, and modifiers of spermatogenic recovery after hormonal male contraception: an integrated analysis. Lancet 2006367 1412-1420. (doi:10.1016/S0140-6736(06)68614-5)

27 Liu PY, Swerdloff RS, Anawalt BD, Anderson RA, Bremner WJ, Elliesen J, Gu YQ, Kersemaekers WM, McLachlan RI, Meriggiola MC et al. Determinants of the rate and extent of spermatogenic during hormonal male contraception: an integrated analysis. Journal of Clinical Endocrinology and Metabolism 200893 1774-1783. (doi:10.1210/jc.2007-2768)

28 Knuth UA, Maniera H \& Nieschlag E. Anabolic steroids and semen parameters in bodybuilders. Fertility and Sterility 198952 1041-1047.

29 Torres-Calleja J, González-Unzaga M, DeCelis-Carrillo R, CalzadaSánchez L \& Pedron N. Effect of androgenic anabolic steroids on sperm quality and serum hormones levels in adult male bodybuilders. Life Sciences 200168 1769-1774. (doi:10.1016/S0024-3205(01)00972-9)

30 Gazvani MR, Buckett W, Luckas MJ, Aird IA, Hipkin LJ \& Lewis-Jones DI. Conservative management of azoospermia following steroid abuse. Human Reproduction 199712 1706-1708. (doi:10.1093/ humrep/12.8.1706)

31 Boyadjiev NP, Georgieva KN, Massaldjieva RI \& Gueorguiev SI. Reversible hypogonadism and azoospermia as a result of anabolicandrogenic steroid use in a bodybuilder with personality disorder. A case report. Journal of Sports Medicine and Physical Fitness 200040 271-274.

32 Gåverik N, Strahm E, Garlw M, Lundmark J, Ståhle L, Ekström L \& Rane A. Long term perturbation of endocrine parameters and cholesterol metabolism after discontinued abuse of anabolic androgenic steroids. Journal of Steroid Biochemistry and Molecular Biology 2011127 295-300. (doi:10.1016/j.jsbmb.2011.08.005)

33 Nieschlag E, Vorona E, Wenk M, Hemker AK, Kamischke A \& Zitzmann M. Hormonal male contraception in men with normal and subnormal semen parameters. International Journal of Andrology 2011 34 556-567. (doi:10.1111/j.1365-2605.2011.01142.x)

34 Lemcke B, Zentgraf J, Behre HM, Kliesch S, Bramswig JH \& Nieschlag E. Long-term effects on testicular function of high-dose testosterone treatment for excessively tall stature. Journal of Clinical Endocrinology and Metabolism 199681 296-301.

35 Hendriks AE, Boellaard WP, van Casteren NJ, Romijn JC, de Jong FH, Boot AM \& Drop SL. Fatherhood in tall men treated with high-dose sex steroids during adolescence. Journal of Clinical Endocrinology and Metabolism 201095 5233-5240. (doi:10.1210/jc.2010-0435) 
36 Froehner M, Fischer R, Leike S, Hakenberg OW, Noack B \& Wirth MP. Intratesticular leiomyosarcoma in a young man after high dose doping with Oral-Turinabol. Cancer 199986 1571-1575. (doi:10.1002/ (SICI) 1097-0142(19991015)86:8 < 1571::AID-CNCR26> 3.0.CO;2-C)

37 Kirkham H \& Algard FT. Characteristic of an androgen/estrogen dependent leiomyosarcoma of the ductus deferens of the Syrian hamster. I. In vivo. Cancer Research 196525 141-146.

38 Finkelstein JS, Lee H, Burnett-Bowie SA, Pallais JC, Yu EW, Borges LF, Jones BF, Barry CV, Wulczyn KE, Thomas BJ et al. Gonadal steroids and body composition, strength, and sexual function in men. New England Journal of Medicine 2013369 1011-1022. (doi:10.1056/ NEJMoa1206168)

39 Jarow JP \& Lipshultz LI. Anabolic steroid-induced hypogonadotropic hypogonadism. American Journal of Sports Medicine 199018 429-431. (doi:10.1177/036354659001800417)

40 Tan RS \& Scally MC. Anabolic steroid-induced hypogonadism towards a unified hypothesis of anabolic steroid action. Medical Hypotheses 200972 723-728. (doi:10.1016/j.mehy.2008.12.042)

41 Coward RM, Rajanahally S, Kovac JR, Smith RP, Pastuszak AW \& Lipshultz LI. Anabolic steroid induced hypogonadism in young men. Journal of Urology 2013190 2200-2205. (doi:10.1016/j.juro. 2013.06.010)

42 Menon DK. Successful treatment of anabolic steroid-induced azoospermia with human chorionic gonadotropin and human menopausal gonadotropin. Fertility and Sterility 200379 1659-1661. (doi:10.1016/ S0015-0282(03)00365-0)

43 Turek PJ, Williams RH, Gilbaugh JH III \& Lipshultz LI. The reversibility of anabolic steroid-induced azoospermia. Journal of Urology 1995153 1628-1630. (doi:10.1016/S0022-5347(01)67482-2)

44 Pirola I, Cappelli C, Delbarba A, Scalvini T, Agosti B, Assanelli D, Bonetti A \& Castellano M. Anabolic steroids purchased on the Internet as a cause of prolonged hypogonadotropic hypogonadism. Fertility and Sterility 201094 2331e1-2331e3. (doi:10.1016/j.fertnstert.2010. 03.042)

45 Karila T, Hovatta O \& Seppälä T. Concomitant abuse of anabolic androgenic steroids and human chorionic gonadotrophin impairs spermatogenesis in power athletes. International Journal of Sports Medicine 200425 257-263. (doi:10.1055/s-2004-819936)

46 Drakeley A, Gazvani R \& Lewis-Jones I. Duration of azoospermia following anabolic steroids. Fertility and Sterility $2004 \mathbf{8 1} 226$. (doi:10.1016/j.fertnstert.2003.10.001)

47 Corona G, Baldi E \& Maggi M. Androgen regulation of prostate cancer: where are we now? Journal of Endocrinological Investigation 201134 232-243. (doi:10.1007/BF03347072)

48 Roberts JT \& Essenhigh DM. Adenocarcinoma of prostate in 40-yearold body-builder. Lancet 19862 742. (doi:10.1016/S01406736(86)90251-5)

49 Pinto F, Sacco E, Volpe A, Gardi M, Totaro A, Calarco A, Racioppi M, Gulino G, D'Addessi A \& Bassi PF. Doping and urologic tumors. Urologia 201077 92-99.

50 Hollingworth M, Harper A \& Hamer M. An observational study of erectile dysfunction, infertility and prostate cancer in regular cyclists: cycling for health UK study. Journal of Men's Health 201411 75-79.

51 Shores MM, Smith NL, Forsberg CW, Anawalt BD \& Matsumoto AM. Testosterone treatment and mortality in men with low testosterone levels. Journal of Clinical Endocrinology and Metabolism 201297 2050-2058. (doi:10.1210/jc.2011-2591)

52 Wistuba J, Nieschlag E, Semjonow A, Sandhowe-Klaverkamp R, Friderichs-Gromoll S, Zitzmann M, Simoni M \& Luetjens CM. Testosterone-induced prostate growth is blocked by co- and preadministration of norethisterone enanthate in castrated cynomolgus monkeys. Urologia Internationalis 201288 358-364. (doi:10.1159/ 000335209)

53 Roupas ND \& Georgopoulos NA. Menstrual function in sports. Hormones 201110 104-116. (doi:10.14310/horm.2002.1300)
54 Orio F, Muscogiuri G, Ascione A, Marciano F, Volpe A, La Sala G, Savastano S, Colao A \& Palomba S. Effects of physical exercise on the female reproductive system. Minerva Endocrinologica $2013 \mathbf{3 8}$ 305-319.

55 Gudmundsdottir SL, Flanders WD \& Augestad LB. Physical activity and fertility in women: the North-Trøndelag Health Study. Human Reproduction 200924 3196-3204. (doi:10.1093/humrep/dep337)

56 Morris SN, Missmer SA, Cramer DW, Powers RD, McShane PM \& Hornstein MD. Effects of lifetime exercise on the outcome of in vitro fertilization. Obstetrics and Gynecology 2006108 938-945. (doi:10.1097/01.AOG.0000235704.45652.0b)

57 Bermon S, Garnier PY, Hirschberg AL, Robinson N, Giraud S, Nicoli R, Baume N, Saugy M, Fénichel P, Bruce SJ et al. Serum androgen levels in elite female athletes. Journal of Clinical Endocrinology and Metabolism 201499 4328-4335. (doi:10.1210/jc.2014-1391)

58 Warren MP \& Perlroth NE. The effects of intense exercise on the female reproductive system. Journal of Endocrinology 2001170 3-11. (doi:10.1677/joe.0.1700003)

59 Thein-Nissenbaum J. Long term consequences of the female athlete triad. Maturitas 201375 107-112. (doi:10.1016/j.maturitas. 2013.02.010)

60 De Souza MJ, Nattiv A, Misra M, Williams NI, Mallinson RJ, Gibbs JC, Olmsted M, Goolsby M, Matheson G, Barrack M et al. 2014 female athlete triad coalition consensus statement on treatment and return to play of the female athlete triad. Current Sports Medicine Reports 201413 219-232. (doi:10.1249/JSR.0000000000000077)

61 Van Staa TP \& Sprafka JM. Study of adverse outcomes in women using testosterone therapy. Maturitas 200962 76-80. (doi:10.1016/j.maturitas.2008.11.001)

62 Davis SR. Testosterone use in women. In Testosterone: Action, Deficiency, Substitution, 4th edn, ch 23, pp 494-516. Eds E Nieschlag, HM Behre \& S Nieschlag. Cambridge: Cambridge University Press, 2012.

63 Urman B, Pride SM \& Yuen BH. Elevated serum testosterone, hirsutism, and virilism associated with combined androgen-estrogen hormone replacement therapy. Obstetrics and Gynecology 199177 595-598.

64 Braunstein GD. Safety of testosterone treatment in postmenopausal women. Fertility and Sterility 200788 1-16. (doi:10.1016/j.fertnstert. 2007.01.118)

65 Walker J \& Adams B. Cutaneous manifestations of anabolicandrogenic steroid use in athletes. International Journal of Dermatology 200948 1044-1048. (doi:10.1111/j.1365-4632.2009.04139.x)

66 Ferriman DM \& Gallwey JD. Clinical assessment of body hair growth in women. Journal of Clinical Endocrinology and Metabolism 196121 1440-1447. (doi:10.1210/jcem-21-11-1440)

67 Nygren U, Södersten M, Falhammar H, Thorén M, Hagenfeldt K \& Nordenskjöld A. Voice characteristics in women with congenital adrenal hyperplasia due to 21-hydroxylase deficiency. Clinical Endocrinology 2009 70 18-25. (doi:10.1111/j.1365-2265.2008.03347.x)

68 Strauss RH, Liggett MT \& Lanese RR. Anabolic steroid use and perceived effects in ten weight-trained women athletes. Journal of the American Medical Association 1985253 2871-2873. (doi:10.1001/jama. 1985.03350430083032)

69 Baker J. A report on alterations to the speaking and singing voices of four women following hormonal therapy with virilizing agents. Journal of Voice 199913 496-507. (doi:10.1016/S0892-1997(99) 80005-8)

70 Wollina U, Pabst F, Schönlebe J, Abdel-Naser MB, Konrad H, Gruner M, Haroske G, Klemm E \& Schreiber G. Side-effects of topical androgenic and anabolic substances and steroids. A short review. Acta Dermatovenerologica Alpina, Pannonica, et Adriatica 2007 16 117-122.

71 Eklöf AC, Thurelius AM, Garle M, Rane A \& Sjöqvist F. The anti-doping hot-line, a means to capture the abuse of doping agents in the Swedish society and a new service function in clinical pharmacology. European Journal of Clinical Pharmacology 200359 571-577. 
72 Zagouri F, Sergentanis TN, Tsigginou A, Dimitrakakis C, Zografos GC, Dimopoulos MA \& Psaltopoulou T. Female breast cancer in Europe: statistics, diagnosis and treatment modalities. Journal of Thoracic Disease 20146 589-590. (doi:10.3978/j.issn.2072-1439.2014.06.18)

73 Fourkala EO, Zaikin A, Burnell M, Gentry-Maharaj A, Ford J, Gunu R, Soromani C, Hasenbrink G, Jacobs I, Dawnay A et al. Association of serum sex steroid receptor bioactivity and sex steroid hormones with breast cancer risk in postmenopausal women. Endocrine-Related Cancer 201219 137-147. (doi:10.1530/ERC-11-0310)

74 Dimitrakakis C. Androgens and breast cancer in men and women. Endocrinology and Metabolism Clinics of North America 201140 533-547. (doi:10.1016/j.ecl.2011.05.007)

75 Wierman ME, Arlt W, Basson R, Davis SR, Miller KK, Murad MH, Rosner W \& Santoro N. Androgen therapy in women: a reappraisal: an Endocrine Society clinical practice guideline. Journal of Clinical Endocrinology and Metabolism 201499 3489-3510. (doi:10.1210/jc. 2014-2260)

76 Gooren LJ, Giltay EJ \& Bunk MC. Long-term treatment of transsexuals with cross-sex hormones: extensive personal experience. Journal of Clinical Endocrinology and Metabolism 200893 19-25. (doi:10.1210/jc. 2007-1809)

77 Mueller A \& Gooren L. Hormone-related tumors in transsexuals receiving treatment with cross-sex hormones. European Journal of Endocrinology 2008159 197-202. (doi:10.1530/EJE-08-0289)

78 Burcombe RJ, Makris A, Pittam M \& Finer N. Breast cancer after bilateral subcutaneous mastectomy in a female-to-male transsexual. Breast 200312 290-293. (doi:10.1016/S0960-9776(03)00033-X)

79 Somboonporn W \& Davis SR. Testosterone effects on the breast: implications for testosterone therapy for women. Endocrine Reviews 200425 374-388. (doi:10.1210/er.2003-0016)

80 De Gooyer ME, Oppers-Tiemissen HM, Leysen D, Verheul HA \& Kloosterboer HJ. Tibolone is not converted by human aromatase to 7alpha-ethynylestradiol ( $7 \alpha$-MEE): analyses with sensitive bioassays for estrogens and androgens and with LC-MSMS. Steroids 200868 235-243. (doi:10.1016/S0039-128X(02)00184-8)

81 Kley HK. Anabole Steroide - pharmakologische Wirkung der Dopingmittel. In Doping und seine Wirkstoffe.Verbotene Arzneimittel im Sport, pp 64-84. Ed D Clasing. Spitta Verlag, 2004.

82 Anderson GL, Limacher M, Assaf AR, Anderson GL, Limacher M, Assaf AR, Bassford T, Beresford SA, Black H, Bonds D et al. Effects of conjugated equine estrogen in postmenopausal women with hysterectomy: the Women's Health Initiative randomized controlled trial. Journal of the American Medical Association 2004291 1701-1712. (doi:10.1001/jama.291.14.1701)

83 Magnusson C, Baron JA, Correia N, Bergström R, Adami H-O \& Persson I. Breast cancer risk following long-term oestrogen and oestsrogen-progestin-replacement therapy. International Journal of Cancer 199981 339-344. (doi:10.1002/(SICI)10970215(19990505)81:3<339::AID-IJC5 > 3.0.CO;2-6)

84 Million Women Study Collaborators . Breast cancer and hormonereplacement therapy in the Million Women Study. Lancet 2003362 419-427. (doi:10.1016/S0140-6736(03)14065-2)

85 Hofling M, Hirschberg AL, Skoog L, Tani E, Hägerström T \& von Schoultz B. Testosterone inhibits estrogen/progestogen-induced breast cell proliferation in postmenopausal women. Menopause 2007 14 183-190. (doi:10.1097/01.gme.0000232033.92411.51)

86 Glaser RL \& Dimitrakakis C. Reduced breast cancer incidence in women treated with subcutaneous testosterone, or testosterone with anastrozole: a prospective, observational study. Maturitas $2013 \mathbf{7 6}$ 342-349. (doi:10.1016/j.maturitas.2013.08.002)

87 Lapointe J, Fournier A, Richard V \& Labrie C. Androgens downregulate bcl-2 prooncogene expression in ZR-75-1 human breast cancer cells. Endocrinology 1999140 416-421.

88 Zhou J, Ng S, Adesanya-Famuiya O, Anderson K \& Bondy CA. Testosterone inhibits estrogen-induced mammary epithelial proliferation and suppresses estrogen receptor expression. FASEB Journal 2000 14 1725-1730. (doi:10.1096/fj.99-0863com)

89 Andò S, De Amicis F, Rago V, Carpino A, Maggiolini M, Panno ML \& Lanzino M. Breast cancer: from estrogen to androgen receptor. Molecular and Cellular Endocrinology 2002193 121-128.

90 Ortmann J, Prifti S, Bohlmann MK, Rehberger-Schneider S, Strowitzki T \& Rabe T. Testosterone and $5 \alpha$-dihydrotestosterone inhibit in vitro growth of human breast cancer cell lines. Gynecological Endocrinology 200216 113-120. (doi:10.1080/713603030)

91 Dimitrakakis C, Jones RA, Liu A \& Bondy CA. Breast cancer incidence in postmenopausal women using testosterone in addition to usual hormone therapy. Menopause 200411 531-535. (doi:10.1097/01. GME.0000119983.48235.D3)

92 Van Winkle W. The action of steroid hormones in mammary cancer. Radiology 194953 530-53991. (doi:10.1148/53.4.530)

93 Zouboulis CC, Chen WC, Thornton MJ, Qin K \& Rosenfield R. Sexual hormones in human skin. Hormone and Metabolic Research 2007 39 85-95. (doi:10.1055/s-2007-961807)

94 Evans NA. Gym and tonic: a profile of 100 male steroid users. British Journal of Sports Medicine 199731 54-58. (doi:10.1136/bjsm.31.1.54)

95 Gerber PA, Kukova G, Meller S, Neumann NJ \& Homey B. The dire consequences of doping. Lancet 2008372 656. (doi:10.1016/S01406736(08)61278-7)

96 Parkinson AB \& Evans NA. Anabolic androgenic steroids: a survey of 500 users. Medicine and Science in Sports and Exercise 200638 644-651. (doi:10.1249/01.mss.0000210194.56834.5d)

97 Elashoff JD, Jacknow AD, Shain SG \& Braunstein GD. Effects of anabolic-androgenic steroids on muscular strength. Annals of Internal Medicine 1991115 387-393. (doi:10.7326/0003-4819-115-5-387)

98 Bhasin S, Storer TW, Berman N, Callegari C, Clevenger B, Phillips J, Bunnell TJ, Tricker R, Shirazi A \& Casaburi R. The effects of supraphysiologic doses of testosterone on muscle size and strength in normal men. New England Journal of Medicine 1996335 1-7. (doi:10.1056/NEJM199607043350101)

99 Hoffman JR \& Ratamess NA. Medical issues associated with anabolic steroid use: are they exaggerated? Journal of Sports Science \& Medicine 20065 182-193.

100 Kersey RD, Elliot DL, Goldberg L, Kanayama G, Leone JE, Pavlovich M, Pope HG Jr \& National Athletic Trainers' Association. National Athletic Trainers' Association position statement: anabolicandrogenic steroids. Journal of Athletic Training 201247 567-588.
Received 23 January 2015

Revised version received 12 March 2015

Accepted 24 March 2015 